OPEN ACCESS

Edited by:

Hiroko Isoda,

University of Tsukuba, Japan

Reviewed by:

Philippe Bourin,

Independent Researcher, Toulouse,

France

Hojjat Naderi-Meshkin,

Queen's University Belfast,

United Kingdom

*Correspondence: Akito Maeda

maeda-aki@phs.osaka-u.ac.jp

Specialty section:

This article was submitted to

Stem Cell Research,

a section of the journal

Frontiers in Cell and Developmental

Biology

Received: 27 March 2020

Accepted: 11 May 2020

Published: 09 June 2020

Citation:

Maeda A (2020) Recruitment

of Mesenchymal Stem Cells

to Damaged Sites by Plant-Derived

Components.

Front. Cell Dev. Biol. 8:437.

doi: 10.3389/fcell.2020.00437

\section{Recruitment of Mesenchymal Stem Cells to Damaged Sites by Plant-Derived Components}

\author{
Akito Maeda* \\ Skin Regeneration, PIAS Collaborative Research, Graduate School of Pharmaceutical Science, Osaka University, Suita, \\ Japan
}

Mesenchymal stem cells (MSCs) are capable of differentiating into a limited number of diverse cells and secrete regenerative factors that contribute to the repair of damaged tissue. In response to signals emitted by tissue damage, MSCs migrate from the bone marrow and area surrounding blood vessels within tissues into the circulating blood, and accumulate at the site of damage. Hence, MSC transplantation therapy is beginning to be applied to the treatment of various intractable human diseases. Recent medicinal plants studies have shown that plant-derived components can activate cell functions. For example, several plant-derived components activate cell signaling pathways, such as phosphatidylinositol 3-kinase and mitogen-activated protein kinase (MAPK), enhance expression of the CXCL12/CXCR4 axis, stimulate extracellular matrix remodeling, and consequently, promote cell migration of MSCs. Moreover, plant-derived components have been shown to promote recruitment of MSCs to damaged tissues and enhance healing in disease models, potentially advancing their therapeutic use. This article provides a comprehensive review of several plant-derived components that activate MSC migration and homing to damaged sites to promote tissue repair.

Keywords: mesenchymal stem cells, cell migration, plant-derived components, cell therapy, tissue repair

\section{INTRODUCTION}

Mesenchymal stem cells (MSCs) are capable of differentiating into a limited yet diverse range of cells, and secrete regenerative factors that contribute to the repair of damaged tissues (Uccelli et al., 2008). MSCs in humans and animals have numerous characteristics, including the expression of specific cell surface markers, some of which are used as criteria for the detection of MSCs in tissues. The International Society for Cellular Therapy proposed that human MSCs should be identified according to positive expression for CD73, CD90, and CD105, and negative for CD11b or CD14, CD19 or CD79 $\alpha$, CD34, CD45, and HLA-DR expression (Dominici et al., 2006). MSCs have been identified in several tissues, including the bone marrow, adipose tissue, cord blood, placenta, and pulp (Pittenger et al., 2019). MSCs have also been reported to migrate to wound sites during the healing process (Wu et al., 2010). Specifically, MSCs have been shown to move from the perivascular area of tissue into the blood circulation in response to signals emitted after tissue damage, and subsequently MSCs in the blood circulation may accumulate in damaged tissue (Rochefort et al., 2006; Iinuma et al., 2015). Thus, MSCs exhibit homing properties, which allows for their spontaneous accumulation at the site of injury. 
It has been shown that methods capable of promoting the migration and homing of MSCs to damaged tissue enhance their effect in cell therapy (Park et al., 2015). These models have been reported to implement several approaches including the preconditioning of MSCs, recombinant MSCs, engineering of cell surface proteins of MSCs, and modification of target tissues (Becker and Riet, 2016). To assess MSC migration in vitro, either the Boyden chamber method or the Transwell method have been used, which examine movement between concentration gradients, created by separating active substances with a permeable membrane, or by the Scratch wound method using movement in two dimensions, respectively (Justus et al., 2014). Alternatively, for the detection of MSC migration in vivo, researchers have developed MSCs labeled with fluorescent dyes, magnetic substances, and radioactive substances, or genetically modified MSCs that express reporters, which are transplanted into a living organism (Krueger et al., 2018). Recently, several clinical trials using cell therapy to transfer exogenous MSCs into the body for treatment of various types of tissue damage and diseases, have demonstrated many advantages and are nearing completion [clinical trials databases: www.clinicaltrials.gov, 306 studies using MSCs with study completed status in February 2020]. The application of MSC therapy has been reported for a broad range of disorders, including various skin diseases, bone defects, cardiac disorders, and brain damage (Kim et al., 2017; Wang et al., 2018; Ward et al., 2018; Presen et al., 2019). In addition, advanced research has been conducted to develop MSCs as cell vectors for application in cancer treatment (Mohr and Zwacka, 2018). Therefore, new materials that enhance the recruitment of transplanted MSCs into damaged tissues, may further improve their therapeutic effect.

Cell migration is stimulated by chemokines, cytokines, growth factors, and other biomolecules, through a number of molecularly and pharmacologically defined signaling pathways (MarquezCurtis and Janowska-Wieczorek, 2013). MSC migration has been shown to be activated by factors such as CXCL12 (SDF-1), MIP-1, HGF, VEGF, and PDGF. Moreover, specific signaling pathway molecules including CXCR4, phosphatidylinositol 3kinase (PI3K), mitogen-activated protein kinase (MAPK), and small $G$ proteins have been reported to be involved in the regulation of MSC migration. It has also been reported that hypoxic preconditioning stimulates the expression of genes involved in cell migration, thereby activating MSC migration (Rochefort et al., 2006; Meng et al., 2018). Upon reaching the target site, MSCs can degrade the intercellular matrix and use as a scaffold to migrate through tissue.

Medicinal plants have historically been used in folk medicine to relieve various symptoms and diseases. Studies of compounds derived from medicinal plants have shown that they can molecularly activate various functions in cells and tissues (Shedoeva et al., 2019). In fact, it has been reported that plantderived components can activate signal transduction pathways related to cell motility (Cho et al., 2014). Although there are few reports concerning plant-related components involved in MSC migration, they represent a promising class of potential candidates to enhance the therapeutic effects of MSC therapy. Nevertheless, it has been reported that plant-derived components activate MSC migration through specific signaling pathways, mobilize MSCs to injured organs, and have healing effects. Moreover, such information may be useful for identifying more effective chemical compounds in the future. Therefore, this article reviews plant-derived components that have been shown to activate MSC migration, and homing, to damaged sites in animal models, where they contribute to the healing process.

\section{ACTIVATION OF MSC MIGRATION BY PLANT-DERIVED COMPONENTS}

Several studies have reported that plant-derived components promote MSC migration, which may contribute to healing of damaged tissue (Table 1). This effect is triggered by stimulating mechanisms involved in MSC migration (Figure 1 and Table 2). Below we discuss the implicated plant-derived components in detail.

\section{Protocatechuic Acid}

The phenolic compound protocatechuic acid (PCA) has been isolated from a number of herbs and edible plants (Khan et al., 2015). PCA has been reported to have various pharmacological effects such as anti-oxidant, anti-inflammatory, anti-hyperglycemic, anti-apoptotic and antimicrobial activity. PCA has also been shown to inhibit the proliferation and migration of airway smooth muscle cells in tracheal inflammatory conditions (Liu Y. D. et al., 2019), while also suppressing the proliferation and migration of cardiac fibroblasts associated with p38 MAPK activation in a cardiac fibrosis model (Song and Ren, 2019).

Additionally, studies on MSC migration, using Transwell assays and gelatin-coated membranes, have shown that PCA isolated from the kernel of Alpinia oxyphylla ( $0.5 \mathrm{mM}$ or more) enhanced adipose tissue-derived mesenchymal stem cell (AMSC) migration (Wang et al., 2008), which subsequently inhibited initiation of early apoptotic events. Furthermore, following PCA treatment, cell morphology and surface markers remained unchanged, and AMSCs retained their osteocyte, adipocyte, and cardiomyocyte-like cell differentiation potential properties. Although PCA has been shown to stimulate AMSC proliferation, while retaining their functional pluripotency (Wang et al., 2009), it has also been reported that PCA has a stimulatory effect on osteocyte differentiation and a suppressive effect on adipocyte differentiation in mouse embryo-derived MSC (Rivera-Piza et al., 2017).

The mechanism associated with PCA-stimulated MSC migration involves an increase in the expression of membranetype matrix metalloproteinase-1 (MT1-MMP) and activation of matrix metalloproteinase-2 (MMP-2) in AMSCs. Since it has been reported that PCA activates three MAPKs (extracellular signal-regulated kinase1/2; Erk1/2, c-Jun N-terminal kinase; JNK and p38), which in turn activate the MMP signal in Schwann cell migration (Ju et al., 2015), PCA may serve to activate MAPKs involved in upstream signaling of MT1-MMP and MMP2 during AMSC migration. However, further studies are required to verify whether various doses of PCA activate MAPKs and promote 
TABLE 1 | Plant-derived components promote MSC migration and healing in animal models.

\begin{tabular}{|c|c|c|c|c|}
\hline Component & $\begin{array}{l}\text { MSC } \\
\text { source }\end{array}$ & Assessment of MSC migration & Therapeutic model and Administration method & References \\
\hline Protocatechuic acid (PCA) & AMSC & Transwell method & - & Wang et al., 2008 \\
\hline Cinnamtannin B-1 & BMSC & $\begin{array}{l}\text { Boyden chamber method, FACS analysis } \\
\text { for MSC marker, Detection of } \\
\text { luc-expressing MSC }\end{array}$ & $\begin{array}{l}\text { Transdermal administration to the mouse model of } \\
\text { skin wound healing }\end{array}$ & Fujita et al., 2015 \\
\hline Cannabinoids & $\begin{array}{l}\text { AMSC, } \\
\text { BMSC }\end{array}$ & $\begin{array}{l}\text { Boyden chamber method, } \\
\text { Immunofluorescent analysis of MSC }\end{array}$ & $\begin{array}{l}\text { Implantation of the component-loaded microspheres } \\
\text { in the rat model of bone-defect }\end{array}$ & $\begin{array}{l}\text { Schmuhl et al., 2014; } \\
\text { Kamali et al., } 2019\end{array}$ \\
\hline Icariin (ICA) & BMSC & $\begin{array}{l}\text { Transwell method, Scratch wound method, } \\
\text { Detection of BrdU-labeled MSC }\end{array}$ & $\begin{array}{l}\text { Preconditioning MSCs were injected intravenously } \\
\text { into the rabbit model of cartilage-defect }\end{array}$ & $\begin{array}{l}\text { Jiao et al., 2018; Zhu } \\
\text { et al., } 2018\end{array}$ \\
\hline Tanshinone IIA (Tan \|A) & BMSC & $\begin{array}{l}\text { Transwell method, Detection of } \\
\text { Dil-labeled MSC }\end{array}$ & $\begin{array}{l}\text { Oral administration to the rat model of acute } \\
\text { myocardial infarction }\end{array}$ & Tong et al., 2011 \\
\hline Astragaloside IV (AS IV) & BMSC & $\begin{array}{l}\text { Transwell method, Detection of } \\
\text { Dio-labeled MSC }\end{array}$ & $\begin{array}{l}\text { Preconditioning MSCs were injected intravenously } \\
\text { into the rat model of acute myocardial infarction }\end{array}$ & Xie et al., 2013 \\
\hline Tetramethylpyrazine (TMP) & BMSC & $\begin{array}{l}\text { Transwell method, Detection of } \\
\text { BrdU-labeled MSC }\end{array}$ & $\begin{array}{l}\text { Preconditioning MSCs were injected intravenously } \\
\text { into the rat model of cerebral ischemia, or } \\
\text { Intraperitoneal administration to the model }\end{array}$ & Li et al., 2017a, 2019 \\
\hline $\begin{array}{l}\text { Guanxin danshen formulation } \\
\text { (GXDS) (Including Tanshinone IIA) }\end{array}$ & BMSC & Detection of GFP-expressing MSC & $\begin{array}{l}\text { Oral administration to the rat model of acute } \\
\text { myocardial infarction }\end{array}$ & Han et al., 2019 \\
\hline
\end{tabular}

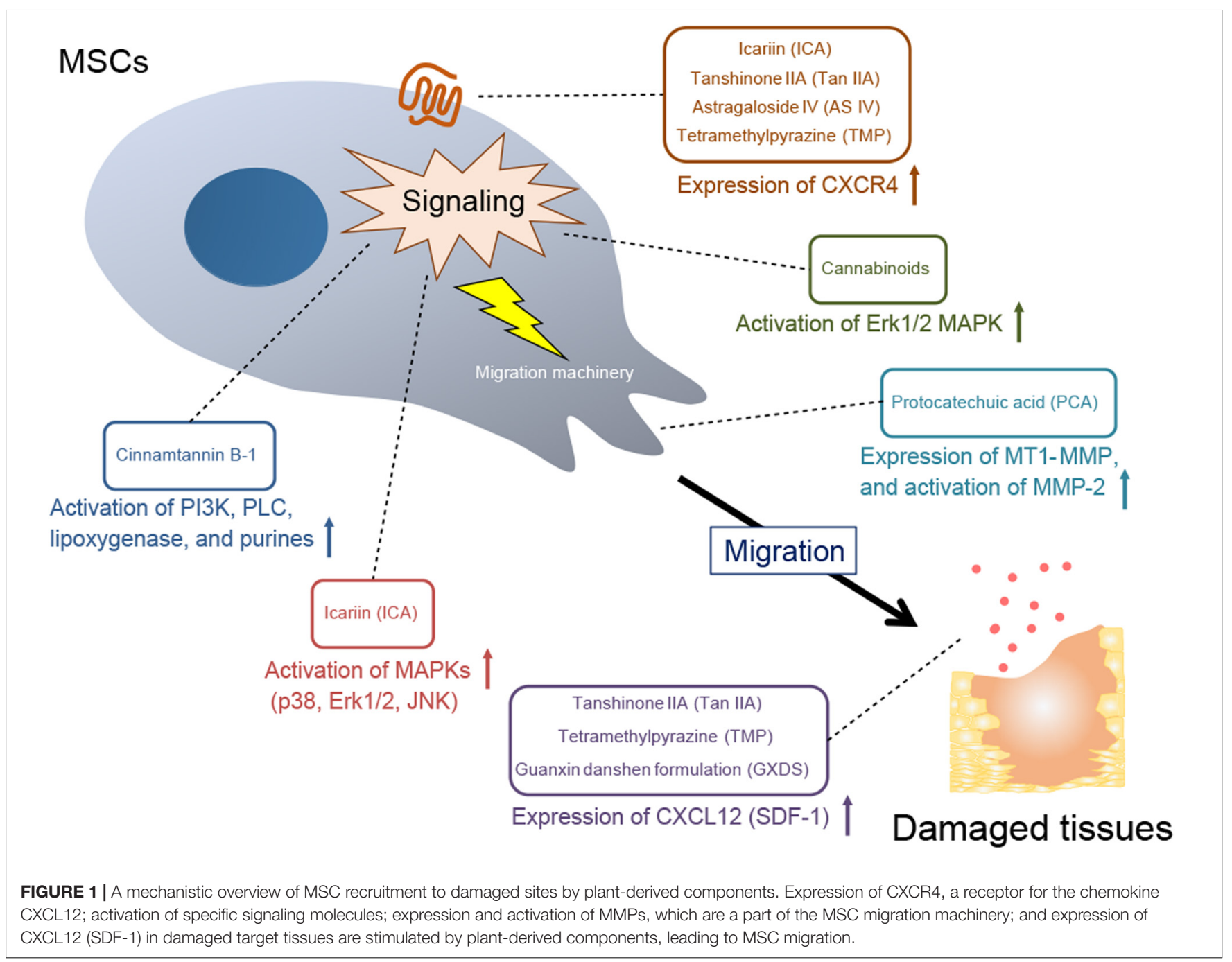


TABLE 2 | Plant-derived components stimulate signaling for MSC migration.

\begin{tabular}{|c|c|c|c|}
\hline Component & MSC source & Effects on MSC migration & References \\
\hline Protocatechuic acid (PCA) & AMSC & Expression of MT1-MMP, and activation of MMP-2 & Wang et al., 2008 \\
\hline Cinnamtannin B-1 & BMSC & Activation of PI3K, PLC, lipoxygenase, and purines & Fujita et al., 2015 \\
\hline Cannabinoids & AMSC & Activation of Erk1/2 MAPK & Schmuhl et al., 2014 \\
\hline Icariin (ICA) & BMSC & Activation of MAPKs (p38, Erk1/2, JNK), and Expression of CXCR4 & Jiao et al., 2018; Zhu et al., 2018 \\
\hline Tanshinone \|A (Tan ॥A) & BMSC & Expression of CXCL12 (SDF-1) in target tissue, and CXCR4 in MSCs & Tong et al., 2011 \\
\hline Astragaloside IV (AS IV) & BMSC & Expression of CXCR4 & Xie et al., 2013 \\
\hline Tetramethylpyrazine (TMP) & BMSC & Expression of CXCL12 (SDF-1) in target tissue, and CXCR4 in MSCs & Li et al., 2017a, 2019 \\
\hline $\begin{array}{l}\text { Guanxin danshen formulation } \\
\text { (GXDS) (Including Tanshinone IIA) }\end{array}$ & BMSC & Expression of CXCL12 (SDF-1) in target tissue & Han et al., 2019 \\
\hline
\end{tabular}

migration of MSCs. MMPs play a key role in AMSC entry and migration through extracellular matrix (ECM) barriers, such as the basement membrane (Nitzsche et al., 2017). In the process of cell migration across the ECM barrier, PCA-stimulated AMSCs may promote pericellular ECM degradation by MMPs, thereby partially promoting cell migration. These studies provide evidence for the mechanism by which PCA may facilitate MSC migration to organs in MSC therapy.

\section{Cinnamtannin B-1}

Cinnamtannin B-1 is a proanthocyanidin found in specific plants such as Cinnamomum zeylanicum (Sánchez-Rubio et al., 2018). Cinnamtannin B-1 exhibits anti-inflammatory, anti-oxidant and anti-thrombotic properties (López et al., 2008), and also protects neurons from ischemia/reperfusion-induced dysfunction (Chi et al., 2013), while inhibiting survival of cancer cells (Carriere et al., 2018), and protecting pancreatic acinar cells during pancreatitis (Rivera-Barreno et al., 2010).

Mallotus philippinensis bark extract also contains cinnamtannin B-1 (Furumoto et al., 2014). The use of this extract has been shown to increase migration of bone marrowderived mesenchymal stem cells (BMSCs) and enhance wound healing in a mouse model (Furumoto et al., 2014). In fact, the efficacy of the extract on BMSC migration has been shown to be higher in comparison to other skin cell types. Histopathological features observed upon treatment with the extract indicated tissue repair by enhancement of angiogenesis and granulation tissue. Mallotus philippinensis fruit glandular hair also promoted wound healing via anti-oxidant and anti-inflammatory activity in a rat model (Gangwar et al., 2015).

Cinnamtannin B-1 has also been shown to promote BMSC migration when administered within the range of $0.8-2 \mu \mathrm{g} / \mathrm{ml}$, and enhanced wound healing in a mouse model following topical administration (1.2 and $2.4 \mu \mathrm{g} /$ wound) (Fujita et al., 2015). Further, examination of BMSC recruitment in blood circulation via cell marker analysis showed that mobilization of endogenous MSCs into the blood increased following cinnamtannin B-1 treatment. Image analysis of an animal model implanted with luciferase-expressing BMSC indicated that cinnamtannin B-1 increased BMSC accumulation at the wound site and promoted wound healing. Furthermore, cinnamtannin B-1-induced BMSC migration was attenuated by inhibitors of PI3K, phospholipase C (PLC), lipoxygenase (LOX), and purine, implicating the associated signaling pathways in BMSC migration. In addition, morelloflavone, a biflavonoid constituent from Garcinia vilersiana Pierre with structural similarities to cinnamtannin B-1, also enhanced BMSC migration with a similar pharmacological profile (Karanjgaokar et al., 1967). Therefore, structurally related compounds may also be effective in treating skin wounds by inducing mobilization of BMSCs.

\section{Cannabinoid}

Cannabinoids are chemical components found in cannabis plants, with more than 100 varieties (Grof, 2018). The two primary types include cannabidiol (CBD) and tetrahydrocannabinol (THC), with the latter serving as the primary psychoactive component. CB1, CB2, TRPV1 and orphan G protein-coupled receptor GPR55, have been reported to exist as endogenous cannabinoid receptors (Hryhorowicz et al., 2018). Cannabinoids have a variety of effects, in addition to their analgesic properties (Kaur et al., 2016). Specifically, cannabinoids inhibit the growth and migration of gliomas (Vaccani et al., 2005), inhibit inflammation via neutrophil recruitment (Schicho et al., 2011), promote wound healing through cell adhesion as well as migration of fibroblasts and keratinocytes (Wang et al., 2016; Liu C. et al., 2019), and promote bone formation by osteoblast regulation (Idris and Ralston, 2012).

It has also been reported that $\mathrm{CBD}$, administered within the range of $0.01-3 \mu \mathrm{M}$, increased AMSC migration in a dosedependent manner (Schmuhl et al., 2014). However, CBDinduced AMSC migration was antagonized by inhibition of the Erk1/2 MAPK pathway via attenuated Erk1/2 phosphorylation in the presence of a CB2 receptor antagonist and GRP55 agonist. Conversely, Erk1/2-dependent migratory effects were observed following stimulating with CB2 receptor agonist and GPR55 antagonist. Thus, the basis for CBD-induced MSC migration involves activation of CB2 or inhibition of GPR55, which subsequently activates Erk1/2. Furthermore, long-term treatment with CBD has been shown to differentiate AMSCs into osteoblasts (Schmuhl et al., 2014). Hence, prolonged incubation of AMSC with CBD may enhance bone regeneration. In fact, recently, using a bone deficient rat model, it was reported that microspheres supplemented with CBD promoted the recruitment of MSCs and regeneration of bone defects (Kamali et al., 2019).

Similarly, the major psychoactive component, $\Delta 9$ tetrahydrocannabinol $(\triangle 9-\mathrm{THC})$, also increased AMSC 
migration (Lüder et al., 2017). In the case of THC, migration of AMSCs is facilitated by CB1 through Erk1/2 activation, although THC has been reported to respond to both $\mathrm{CB} 1$ and CB2 (Pertwee, 2008). However, since cannabinoids can respond to many functional proteins, further research is needed to obtain a complete understanding of their pharmacological effects (Hryhorowicz et al., 2018).

\section{Icariin}

Icariin (ICA) is a flavonoid glycoside isolated from Epimedium and is a primary component of the Chinese herb Herba Epimedii ( $\mathrm{Li}$ et al., 2015). It has been reported that ICA possesses broad therapeutic activities, such as anti-oxidant, tonic, aphrodisiac, neuro-protective, cardio-protective, anti-rheumatic, anti-cancer, and anti-osteoporotic effects (Li et al., 2015). ICA has also been reported to promote BMSC proliferation, bone formation, and chondrogenic differentiation (Wang et al., 2014; Qin et al., 2015). Furthermore, treatment of AMSCs with ICA in a rat model of diabetes-related erectile dysfunction, protected against oxidative stress via PI3K signaling and improved AMSC survival, leading to enhanced therapeutic potential (Wang X. et al., 2017). Furthermore, combining ICA and MSCs was shown to promote angiogenesis and neurogenesis, as a result of increased production of VEGF and brain-derived neurotrophic factor (BDNF) through activation of PI3K and Erk1/2 MAPK, in an ischemic stroke rat model (Liu D. et al., 2018). ICA may also improve wound and periodontal pathology by promoting keratinocyte proliferation and migration, as well as by promoting survival and migration of periodontal ligament fibroblasts (Liu H. J. et al., 2018; Mi et al., 2018).

ICA administered at $1 \mu \mathrm{M}$ was reported to significantly increase BMSC migration by stimulating actin stress fiber formation (Jiao et al., 2018). MAPK signals, such as p38, Erk1/2 and JNK, were activated during BMSC migration following ICA stimulation. In the presence of MAPK inhibitors, BMSC migration was also inhibited, and actin stress fiber formation was abolished. Thus, ICA may promote BMSC migration by increasing actin stress fiber formation through MAPK signaling. ICA also promotes CXCR4 expression, which is a signaling molecule upstream of MAPK, in BMSC migration through the activation of hypoxia inducible factor-1 (HIF-1) (Zhu et al., 2018). Moreover, transplantation of ICA-treated BMSCs in a cartilagedeficient rabbit model, accelerated the migration of BMSCs to the cartilage-deficient region in comparison to non-treated BMSCs (Jiao et al., 2018). These results suggest that ICA-treated BMSC may be effective in treating cartilage defects.

\section{Tanshinone IIA}

Tanshinone IIA (Tan IIA) is a diterpene quinone and one of the major active compounds of Salvia miltiorrhiza (Lamiaceae) (Ren et al., 2019). Salvia miltiorrhiza has been widely used as a herbal medicine in the clinical treatment of cardiovascular diseases $(\mathrm{Li}$ et al., 2018a). Tan IIA has anti-oxidant and anti-inflammatory properties as well as multiple pharmacological benefits such as cardio-protection, neuroprotection, vascular protection, and anti-cancer effects (Li et al., 2018a; Ren et al., 2019). As for cell migration, Tan IIA has been shown to inhibit vascular endothelial cell proliferation and migration by inhibiting VEGF expression and its signaling pathways (Xing et al., 2015; Fan et al., 2017; Lee et al., 2017).

Tan IIA has been reported to have an effect on MSC differentiation including promoting osteogenic differentiation in BMSCs (Qian et al., 2015), cord blood MSCs (Heo et al., 2017), Wharton's jelly MSCs (Cabrera-Pérez et al., 2019), and periodontal ligament stem cells (Liu X. et al., 2019). In addition, Tan IIA effectively induced the differentiation of cord blood MSCs into liver cells in a rat model of cirrhosis (Yang et al., 2015), BMSCs into neuronal cells in a rat spinal cord injury model (Zhang et al., 2018), and placental MSCs into cardiomyocytes in vitro ( $\mathrm{Li} \mathrm{K}$. et al., 2018). Furthermore, it has been reported that Tan IIA combined with MSC treatment exhibited a neuronal protective effect via suppression of neuronal apoptosis in a vascular dementia rat model (Kong et al., 2017), as well as by suppressing amyloid-related protein production and inflammation in an $\mathrm{A} \beta 25$-35-induced $\mathrm{AD}$ rat model (Huang et al., 2019).

Additionally, administration of 1-4 $\mu \mathrm{M}$ Tan IIA has been shown to significantly enhance BMSC migration (Tong et al., 2011). In a rat model of acute myocardial infarction, oral administration of Tan IIA at $30 \mathrm{mg} / \mathrm{kg} / \mathrm{d}$ combined with BMSC transplantation increased BMSC recruitment to the damaged area following myocardial infarction, resulting in restored normal function of the left ventricle (LV) systolic and end-diastolic pressure, as well as enhanced VEGF expression in the infarcted region. Immunological detection of the occlusion site also suggests that Tan IIA may promote CXCL12 expression in the infarcted area, while increasing CXCL12 levels in peripheral blood. However, Tan IIA-induced BMSC migration was inhibited by a CXCR4 blocker. Furthermore, Tan IIA treatment was shown to enhance CXCR4 expression in BMSCs. These results suggest that Tan IIA increases CXCL12 expression at the site of injury, and increases BMSC migration by enhancing CXCR4 expression in BMSCs. Thus, Tan IIA may be effective in treating ischemic heart disease by MSC therapy.

\section{Astragaloside IV}

Astragaloside IV (AS IV) is an active saponin and the major active ingredient of Astragalus membranaceus, used in traditional Chinese medicine (Li et al., 2017b). Astragalus membranaceus, commonly used with $S$. miltiorrhiza including Tan IIA, is commonly used to enhance cardiovascular disease protection (Wang D. et al., 2017). Moreover, AS IV has demonstrated pharmacological action for cerebral injury, cardiovascular disease, liver, diabetic nephropathy, and cancer (Li et al., 2017b). It has also been shown to reduce infarct size and arrhythmias, while improving ventricular function in ischemic heart disease (Xu et al., 2007). In cell migration, AS IV treatment enhances the proliferation and migration of a human osteoblast-like cell line, which may be facilitated by activation of the Hedgehog signaling pathway (Guo et al., 2019). AS IV also inhibits proliferation and migration of human dermal vascular smooth muscle cells, stimulated by PDGF-BB secreted during vascular injury, through inhibition of p38 MAPK signaling (Chen et al., 2014). It has also 
been reported that AS IV and Tan IIA promote tubular structure formation of BMSC-derived endothelial cell cells, similar to that of blood vessels, via the expression of connexins and cell connection (Li et al., 2018b).

Lastly, BMSCs stimulated with AS IV, administered at $0.4 \mu \mathrm{g} / \mathrm{ml}$, was reported to increase CXCR4 expression, indicating that BMSC migration to its ligand CXCL12 was enhanced (Xie et al., 2013). In addition, this enhanced migration was suppressed by CXCR4 inhibitors. Additionally, in a rat model of acute myocardial infarction, BMSCs stimulated with AS IV displayed increased homing to ischemic myocardial sites, suggesting that AS IV enhances BMSC recruitment via increased CXCR4 expression. Although the effect of AS IV on MSC migration was not as strong as that observed with Tan IIA, when the two components are administered together, a synergistic enhancement of BMSC migration was observed, hence this combinatorial strategy may increase the efficacy of MSC transplant therapy.

\section{Tetramethylpyrazine}

Tetramethylpyrazine (TMP) is pyrazine and an alkaloid isolated from Rhizoma Chuanxiong (Ligusticum wallichii) (Zhao et al., 2016). TMP functions as a neuro-protective, anti-apoptotic, anticancer, vasodilator, and anti-inflammatory agent (Zhao et al., 2016). With respect to cell migration, TMP increases brain microvascular endothelial cell proliferation and migration by partially increasing VEGF secretion (Zhang et al., 2014), and promoting migration of the neural progenitor by inducing CXCL12 expression through activation of the PI3K pathway (Kong et al., 2016). Alternatively, TMP inhibits the migration of neutrophils activated by inflammation in a rat cerebral ischemia model, which was reported to involve Akt and Erk signaling (Chang et al., 2015).

TMP was also shown to enhance growth and neuronal differentiation of BMSCs. Further, it was suggested to have antiaging effects on the nervous system (Song et al., 2019). A Chinese therapy, the Jiuxin pill, containing TMP and borneol, is known to promote exosome secretion from cardiac MSCs, which may have a positive therapeutic effect on heart disease (Ruan et al., 2018). In MSC migration, pretreatment with 10-200 $\mu \mathrm{M}$ TMP, causes increased BMSC migration in a dose-dependent manner (Li et al., 2017a). TMP also promoted CXCR4 expression, which was inhibited by a CXCR4 blocker. Intravenous administration of TMP-pretreated BMSCs into a cerebral ischemic rat model demonstrated improved neurological function and enhanced recruitment of BMSCs to cerebral ischemic sites. In addition, angiogenesis and the expression of both CXCL12 and CXCR4 were promoted at the ischemia site. In a separate study, the combination of transplanted BMSCs and intraperitoneal administration of TMP $(40 \mathrm{mg} / \mathrm{kg} / \mathrm{d})$ in a cerebral ischemia model not only promoted the CXCL12/CXCR4 axis, but also regenerated blood vessels and nerves via enhancement of VEGF and BDNF expression, leading to functional recovery ( $\mathrm{Li}$ et al., 2019). Taken together, these results show that the combination of MSCs and TMP may contribute to CXCL12/CXCR4 axis augmentation and neuronal regeneration, suggesting that they may be effective in treating cerebral ischemic injury.

\section{Guanxin Danshen Formulation}

Guanxin Danshen (GXDS), a Chinese herbal medicine, is an effective formulation for the treatment of ischemic heart diseases (Deng et al., 2017). The GXDS formulation is comprised of three materials: Salvia miltiorrhiza (Lamiaceae), Panax notoginseng (Lamiaceae), and Dalbergia odorifera (Fabaceae). It contains Tanshinone IIA, salvianolic acid B (Wang et al., 2013), ginsenoside Rb1, ginsenoside RG1, notoginsenoside R1 (Wan et al., 2007), and flavanols (Liu et al., 2005).

GXDS has also proven effective in MSC treatments. For instance, oral administration of GXDS $(100 \mathrm{mg} / \mathrm{kg} / \mathrm{d})$ in combination with BMSC transplantation in a rat model of acute myocardial infarction improved cardiac function of the LV ejection fraction, LV fractional shortening, and LV end-systolic volume (Han et al., 2019). In addition, GXDS administration in combination with BMSC transplantation not only reduced cell apoptosis detected by TUNEL staining, but also enhanced periand infarcted angiogenesis, increased local CXCL12 expression and the number of BMSCs homing to the infarcted area, while also reducing the size of the myocardial infarction region. Therefore, it is suggested that GXDS increases the migration of MSCs by up-regulating the expression of CXCL12 at the site of infarction. However, since this formulation may contain Tan IIA, it is possible that this component could have contributed to the observed effects (Tong et al., 2011). Nevertheless, the combination of GXDS and MSC therapy has the potential to improve ischemic heart disease, including myocardial infarction.

Moreover, other Chinese herbal extracts have been shown to stimulated MSC migration. For example, oily extract from Catharmus tinctorius $(1-50 \mu \mathrm{g} / \mathrm{ml})$ promotes rat BMSC migration through Rho-associated protein kinase 2 (ROCK2) signaling in vitro (Liu X. et al., 2019). In addition, Bushen Huoxue decoction $(100 \mu \mathrm{g} / \mathrm{ml})$, a mixture comprised of eleven Chinese herbs, increase rat BMSC migration in vitro by regulating MiR539-5p miRNA (Hu et al., 2019) and activating Wnt5a-related cell motility (Shen et al., 2018). Despite these observations, none of the individual compounds responsible have been identified from these extracts.

\section{DISCUSSION}

This article focused on a comprehensive review of plantderived components that increase MSC migration and promote recovery from tissue damage. Studies on the promotion of MSC migration by plant-derived components have exposed a variety of characteristics and advantages (Tables 1, 2). For example, although PCA was only found to be effective at high doses, its potential has been demonstrated and has been suggested to function by increasing the expression and activation of MMPs, which then degrade the ECM to enhance MSC invasion into tissues (Wang et al., 2008). Studies on cinnamtannin B-1 have shown that structurally related flavonoids also have MSC migration activity (Fujita et al., 2015). Thus, expanding upon this structural framework offers the potential to develop more active compounds through structure-based drug development. Since CBD, a non-psychoactive cannabinoid, can promote MSC 
TABLE 3 | Therapeutic effects of plant-derived components and their effects on MSCs.

\begin{tabular}{|c|c|c|c|c|}
\hline Component & Plant & Therapeutic effects of component & Effects of component on MSC & $\begin{array}{l}\text { Therapeutic model by } \\
\text { component and MSC } \\
\text { transplantation }\end{array}$ \\
\hline $\begin{array}{l}\text { Protocatechuic } \\
\text { acid (PCA) }\end{array}$ & $\begin{array}{l}\text { Alpinia oxyphylla } \\
\text { (Zingiberaceae) Khan et al., } \\
2015\end{array}$ & $\begin{array}{l}\text { Anti-oxidant, Anti-inflammatory, } \\
\text { Anti-hyperglycemic, Anti-apoptotic, } \\
\text { Antimicrobial Khan et al., 2015, } \\
\text { Inhibition of the proliferation and } \\
\text { migration of airway smooth muscle } \\
\text { cells in tracheal inflammatory conditions } \\
\text { Liu Y. D. et al., 2019, Suppression of } \\
\text { the proliferation and migration of } \\
\text { cardiac fibroblasts in a cardiac fibrosis } \\
\text { Song and Ren, 2019, Activation of the } \\
\text { MMP signal in Schwann cell migration } \\
\text { Ju et al., } 2015\end{array}$ & $\begin{array}{l}\text { Migration Wang et al., 2008, } \\
\text { Proliferation Wang et al., 2009, } \\
\text { Stimulatory on osteocyte differentiation } \\
\text { and suppressive on adipocyte } \\
\text { differentiation Rivera-Piza et al., } 2017\end{array}$ & - \\
\hline Cinnamtannin B-1 & $\begin{array}{l}\text { Mallotus philippinensis } \\
\text { (Euphorbiaceae) Furumoto } \\
\text { et al., } 2014\end{array}$ & $\begin{array}{l}\text { Anti-oxidant, Anti-inflammatory, } \\
\text { Anti-thrombotic López et al., 2008, } \\
\text { Neuro-protective Chi et al., 2013, } \\
\text { Pancreatic-protective Rivera-Barreno } \\
\text { et al., 2010, Anti-cancer Carriere et al., } \\
\text { 2018, Wound healing Gangwar et al., } \\
2015\end{array}$ & $\begin{array}{l}\text { Migration Furumoto et al., 2014; Fujita } \\
\text { et al., } 2015\end{array}$ & $\begin{array}{l}\text { Wound healing Fujita et al., } \\
2015\end{array}$ \\
\hline Cannabinoids & $\begin{array}{l}\text { Cannabis sativa } \\
\text { (Cannabaceae) Grof, } 2018\end{array}$ & $\begin{array}{l}\text { Analgesic effects Kaur et al., 2016, } \\
\text { Anti-inflamatory Schicho et al., 2011, } \\
\text { Anti-gliomas Vaccani et al., 2005, } \\
\text { Wound healing Wang et al., 2016; Liu } \\
\text { C. et al., 2019, Bone formation Idris } \\
\text { and Ralston, } 2012\end{array}$ & $\begin{array}{l}\text { Migration Schmuhl et al., 2014; Lüder } \\
\text { et al., 2017, Osteocyte differentiation } \\
\text { Schmuhl et al., } 2014\end{array}$ & $\begin{array}{l}\text { Bone-defect Kamali et al., } \\
2019\end{array}$ \\
\hline Icariin (ICA) & $\begin{array}{l}\text { Epimedium (Berberidaceae) } \\
\text { Li et al., } 2015\end{array}$ & $\begin{array}{l}\text { Anti-oxidant, Tonic, Aphrodisiac, } \\
\text { Neuro-protective, Cardio-protective, } \\
\text { Anti-rheumatic, Anti-cancer, } \\
\text { Anti-osteoporotic Li et al., 2015, Wound } \\
\text { healing by effects for keratinocyte } \\
\text { proliferation and migration Mi et al., } \\
2018 \text {, Improvement of periodontal } \\
\text { pathology by effects for survival and } \\
\text { migration of periodontal ligament } \\
\text { fibroblasts Liu H. J. et al., } 2018\end{array}$ & $\begin{array}{l}\text { Migration Jiao et al., 2018; Zhu et al., } \\
\text { 2018, Proliferation, Osteocyte } \\
\text { differentiation Qin et al., 2015, } \\
\text { Chondrogenic differentiation Wang } \\
\text { et al., 2014, Cell survival Wang X. et al., } \\
\text { 2017, Neuronal regeneration in } \\
\text { cooperation with MSCs Liu D. et al., } \\
2018\end{array}$ & $\begin{array}{l}\text { Cartilage-defect Jiao et al., } \\
\text { 2018, Diabetes-associated } \\
\text { erectile dysfunction Wang } \\
\text { X. et al., 2017, Cerebral } \\
\text { ischemia Liu D. et al., } 2018\end{array}$ \\
\hline $\begin{array}{l}\text { Tanshinone IIA (Tan } \\
\text { IIA) }\end{array}$ & $\begin{array}{l}\text { Salvia miltiorrhiza } \\
\text { (Lamiaceae) Ren et al., } \\
2019\end{array}$ & $\begin{array}{l}\text { Anti-oxidant, Anti-inflammatory, } \\
\text { Cardio-protective, Neuro-protective, } \\
\text { Vascular- protective, Anti-cancer Li } \\
\text { et al., 2018a; Ren et al., } 2019 \text { Inhibition } \\
\text { of vascular endothelial cell proliferation } \\
\text { and migration in angiogenesis-related } \\
\text { pathologies Xing et al., 2015; Fan et al., } \\
\text { 2017; Lee et al., } 2017\end{array}$ & $\begin{array}{l}\text { Migration Tong et al., 2011, Osteogenic } \\
\text { differentiation Qian et al., 2015; Heo } \\
\text { et al., 2017; Cabrera-Pérez et al., 2019; } \\
\text { Liu X. et al., 2019, Hepatocyte } \\
\text { differentiation Yang et al., 2015, } \\
\text { Neuronal differentiation Zhang et al., } \\
\text { 2018, Cardiomyocyte differentiation Li } \\
\text { K. et al., 2018, Neuro-protection in } \\
\text { cooperation with MSCs Kong et al., } \\
\text { 2017; Huang et al., } 2019\end{array}$ & $\begin{array}{l}\text { Acute myocardial infarction } \\
\text { Tong et al., } 2011 \text { Liver } \\
\text { cirrhosis Yang et al., 2015, } \\
\text { Spinal cord injury Zhang } \\
\text { et al., 2018, Vascular } \\
\text { dementia Kong et al., 2017, } \\
\text { A } 325-35-i n d u c e d ~ A D \\
\text { Huang et al., } 2019\end{array}$ \\
\hline $\begin{array}{l}\text { Astragaloside IV } \\
\text { (AS IV) }\end{array}$ & $\begin{array}{l}\text { Astragalus membranaceus } \\
\text { (Leguminosae) Li et al., } \\
2017 b\end{array}$ & $\begin{array}{l}\text { Anti-oxidant, Anti-inflammatory, } \\
\text { Cardio-protective, Neuro-protective, } \\
\text { Hepato-protective, Nephro-protective, } \\
\text { Anti-cancer Li et al., 2017b, } \\
\text { Improvement of ventricular function in } \\
\text { ischemic heart disease Xu et al., } 2007 \text {, } \\
\text { Enhancement of the proliferation and } \\
\text { migration of a human osteoblast-like } \\
\text { cell Guo et al., 2019, Inhibition of the } \\
\text { abnormal proliferation and migration of } \\
\text { human dermal vascular smooth muscle } \\
\text { cells Chen et al., } 2014\end{array}$ & $\begin{array}{l}\text { Migration Xie et al., 2013, Angiogenesis } \\
\text { of MSC-derived endothelial cell-like } \\
\text { cells by co-stimulation with Tan IIA Li } \\
\text { et al., 2018b }\end{array}$ & $\begin{array}{l}\text { Acute myocardial infarction } \\
\text { Xie et al., } 2013\end{array}$ \\
\hline
\end{tabular}


TABLE 3 | Continued

\begin{tabular}{|c|c|c|c|c|}
\hline Component & Plant & Therapeutic effects of component & Effects of component on MSC & $\begin{array}{l}\text { Therapeutic model by } \\
\text { component and MSC } \\
\text { transplantation }\end{array}$ \\
\hline $\begin{array}{l}\text { Tetramethylpyrazine } \\
\text { (TMP) }\end{array}$ & $\begin{array}{l}\text { Rhizoma Chuanxiong } \\
\text { (Ligusticum wallichii) Zhao } \\
\text { et al., } 2016\end{array}$ & $\begin{array}{l}\text { Anti-oxidant, Anti-inflammatory, } \\
\text { Neuro-protective, Anti-apoptotic, } \\
\text { Anti-cancer, Vasodilator Zhao et al., } \\
\text { 2016, Increase of brain microvascular } \\
\text { endothelial cell proliferation and } \\
\text { migration Zhang et al., 2014, Promotion } \\
\text { of migration of the neural progenitor } \\
\text { Kong et al., 2016, Inhibition of the } \\
\text { migration of neutrophils activated by } \\
\text { inflammation Chang et al., } 2015 \text {. }\end{array}$ & $\begin{array}{l}\text { Migration Li et al., 2017a, 2019, } \\
\text { Neuronal differentiation Song et al., } \\
\text { 2019, Jiuxin pill containing TMP } \\
\text { promotes exosome secretion from } \\
\text { MSCs Ruan et al., } 2018 \text { Angiogenesis } \\
\text { in cooperation with MSCs Li et al., } \\
\text { 2017a, } 2019 \text { Neurogenesis in } \\
\text { cooperation with MSCs Li et al., } 2019\end{array}$ & $\begin{array}{l}\text { Cerebral ischemia Li et al., } \\
2017 a, 2019\end{array}$ \\
\hline $\begin{array}{l}\text { Guanxin danshen } \\
\text { formulation (GXDS) } \\
\text { (Including } \\
\text { Tanshinone IIA) }\end{array}$ & $\begin{array}{l}\text { Salvia miltiorrhiza (Lamiaceae), } \\
\text { Panax notoginseng } \\
\text { (Lamiaceae), Dalbergia } \\
\text { odorifera (Fabaceae) Deng } \\
\text { et al., } 2017\end{array}$ & Cardio-protective Deng et al., 2017 & Migration Han et al., 2019 & $\begin{array}{l}\text { Acute myocardial infarction } \\
\text { Han et al., } 2019\end{array}$ \\
\hline
\end{tabular}

migration and bone differentiation, and is currently being therapeutically developed, for example in sustained-release drugs from the encapsulated microspheres of biodegradable polymers, it represents a potentially advanced option for bone repair (Schmuhl et al., 2014; Kamali et al., 2019). ICA, when used to pretreat MSCs, promote their migration to cartilage-defect sites (Jiao et al., 2018; Zhu et al., 2018), as well as their proliferation (Qin et al., 2015), bone differentiation (Li et al., 2015), and cartilage differentiation (Wang et al., 2014), and thus, may significantly improve healing related to skeletal defects. Tan IIA has been shown to increase CXCL12 expression at the site of injury as well as CXCR4 on transplanted MSCs, leading to enhanced MSC migration to the injured area, which may prove effective in the treatment of ischemic heart disease (Tong et al., 2011). Interestingly, AS IV and Tan IIA were found to synergistically enhance MSC migration, thus presenting potential for combined therapeutic approaches involving plantderived components (Xie et al., 2013). The use of TMP in combination with MSCs, or as a pretreatment agent, not only promotes the migration of MSCs to the site of injury, but also enhances the effect of MSCs on the regeneration of nerves and blood vessels (Li et al., 2017a, 2019). Consequently, TMP has potential for the treatment of cerebral ischemia damage. Finally, GXDS, when administered orally, in combination with MSC transplantation, may improve acute myocardial infarction by reducing apoptosis at the site of injury, generating new blood vessels, and promoting MSC migration by increasing CXCL12 expression (Han et al., 2019).

The diverse array of mechanisms by which plant-derived components facilitate MSC migration include ECM remodeling, activation of intracellular signaling pathways, such as PI3K and MAPK, and enhanced expression of the CXCL12/CXCR4 axis (Figure 1 and Table 2). The plants from which these compounds have been isolated have been used in traditional medicine practices and as such, a significant amount of useful information is available with regard to their use in several indications. Many associated factors have already been analyzed in detail, including their identification, structural classification and therapeutic efficacy. Since each plant-derived component exhibits therapeutic effects in specific conditions, the disease models are designed based on the indication of the components, expecting the synergistic effects in MSC therapy (Table 3). Consequently, these disease models have demonstrated the benefits of MSC treatment as well as the additional therapeutic effects of many plant-derived components. Furthermore, medicinal plants have many uses and often have the advantage of being administered orally. The methods of administering plant-derived components in vivo for MSC migration enhancement include MSC pretreatment, as well as transdermal, intravenous, intraperitoneal and oral approaches.

Mesenchymal stem cells are believed to play an important role in tissue regeneration after organ damage, and MSC-based therapeutic approaches have been implemented in a variety of disease models (Pittenger et al., 2019). Methods to control the kinetics of transplanted MSCs can be very useful in a variety of applications, including organ regeneration, protection from tissue damage, and treatment of refractory cancers (Park et al., 2015; Becker and Riet, 2016). Herein, we have provided a comprehensive review of plant-derived components that control the migration of MSCs, and may offer novel therapeutic options for regenerative medicine.

\section{Challenges and Future Prospects}

Currently, a gap exists between cell-level migration and in vivo recruitment. Additionally, several issues have been described including, how to achieve specificity and effective dosing for MSC in vivo, how to confirm component toxicity, and how to address the limitations of MSC dynamic tracking technology in vivo for cell kinetic analysis of MSC transplant (Krueger et al., 2018). To solve these issues, tests for drug development must determine the tissue specificity and effective dose of each component in vivo, as well as analyze individual toxicity.

As a supplement to cell dynamic analysis, it is also necessary to accumulate omics information on the effects of plantderived components on MSC mobilization in disease models. For example, with the progress of MSC research, analysis of 
single cells using techniques such as RNA-Seq, will allow for examination of detailed cellular functions along with the MSC fates at the genetic level (Liu S. et al., 2019). Moreover, the effects and suitability of plant-derived components in various MSCs at the genetic level may be elucidated. Furthermore, it has been shown that exosomes secreted by MSCs have a healing effect, and contain a large number of biomolecules such as miRNAs, cytokines, growth factors and enzymes, thereby demonstrating that advances are being made in defining the molecular basis for the therapeutic action of MSCs (Yin et al., 2019).

\section{CONCLUSION}

Plant-derived components, which promote MSC migration, accelerate the healing of tissue damage. Moreover, MSC migration by plant-derived components may be mediated by signaling molecules such as CXCL12/CXCR4, PI3K, MAPK, and MMPs. Ingredients derived from medicinal plants are useful as there already exists invaluable information on medicinal plants for traditional use. In addition, the structural characteristics of plant-derived components are important to understand their

\section{REFERENCES}

Becker, A. D., and Riet, I. V. (2016). Homing and migration of mesenchymal stromal cells: how to improve the efficacy of cell therapy? World J. Stem Cells. 8, 73-87. doi: 10.4252/wjsc.v8.i3.73

Cabrera-Pérez, R., Monguió-Tortajada, M., Gámez-Valero, A., Rojas-Márquez, R., Borràs, F. E., Roura, S., et al. (2019). Osteogenic commitment of Wharton's jelly mesenchymal stromal cells: mechanisms and implications for bioprocess development and clinical application. Stem Cell. Res. Ther. 10:356. doi: 10.1186/ s13287-019-1450-3

Carriere, P. P., Kapur, N., Mir, H., Ward, A. B., and Singh, S. (2018). Cinnamtannin B-1 inhibits cell survival molecules and induces apoptosis in colon cancer. Int. J. Oncol. 53, 1442-1454. doi: 10.3892/ijo.2018.4489

Chang, C. Y., Kao, T. K., Chen, W. Y., Ou, Y. C., Li, J. R., Liao, S. L., et al. (2015). Tetramethylpyrazine inhibits neutrophil activation following permanent cerebral ischemia in rats. Biochem. Biophys. Res. Commun. 463, 421-427. doi: 10.1016/j.bbrc.2015.05.088

Chen, Z., Cai, Y., Zhang, W., Liu, X., and Liu, S. (2014). Astragaloside IV inhibits platelet-derived growth factor-BB-stimulated proliferation and migration of vascular smooth muscle cells via the inhibition of p38 MAPK signaling. Exp. Ther. Med. 8, 1253-1258. doi: 10.3892/etm.2014.1905

Chi, Z., Ma, X., Cui, G., Li, M., and Li, F. (2013). Cinnamtannin B-1 regulates cell proliferation of spinal cord astrocytes and protects the cell from oxygenglucose-serum deprivation/reoxygenation-induced apoptosis. Int. J. Mol. Sci. 14, 15827-15837. doi: 10.3390/ijms140815827

Cho, M., Yoon, H., Park, M., Kim, Y. H., and Lim, Y. (2014). Flavonoids promoting HaCaT migration: I. Hologram quantitative structure-activity relationships. Phytomedicine 21, 560-569. doi: 10.1016/j.phymed.2013.10.006

Deng, X., Xing, X., Sun, G., Xu, X., Wu, H., Li, G., et al. (2017). Guanxin Danshen formulation protects against myocardial ischemia reperfusion injuryinduced left ventricular remodeling by upregulating estrogen receptor B. Front. Pharmacol. 8:777. doi: 10.3389/fphar.2017.00777

Dominici, M., Le Blanc, K., Mueller, I., Slaper-Cortenbach, I., Marini, F., Krause, D., et al. (2006). Minimal criteria for defining multipotent mesenchymal stromal cells. the international society for cellular therapy position statement. Cytotherapy 8, 315-317. doi: 10.1080/14653240600855905

Fan, K., Li, S., Liu, G., Yuan, H., Ma, L., and Lu, P. (2017). Tanshinone IIA inhibits high glucose-induced proliferation, migration and vascularization of human retinal endothelial cells. Mol. Med. Rep. 16, 9023-9028. doi: 10.3892/mmr.2017. 7743 effect on MSC migration activity, and may be potential seeds for drug discovery. Therefore, plant-derived components that enhance MSC recruitment to damaged sites may provide novel tools for improved treatment approaches.

\section{AUTHOR CONTRIBUTIONS}

AM contributed to the design and implementation of the research and writing of the manuscript.

\section{FUNDING}

This work was supported by Budget for Joint Research at the Osaka University (J170901076).

\section{ACKNOWLEDGMENTS}

We would like to thank Editage (www.editage.com) for English language editing.

Fujita, K., Kuge, K., Ozawa, N., Sahara, S., Zaiki, K., Nakaoji, K., et al. (2015). Cinnamtannin B-1 promotes migration of mesenchymal stem cells and accelerates wound healing in mice. PLoS One 10:e0144166. doi: 10.1371/journal. pone. 0144166

Furumoto, T., Ozawa, N., Inamia, Y., Toyoshima, M., Fujita, K., Zaiki, K., et al. (2014). Mallotus philippinensis bark extracts promote preferential migration of mesenchymal stem cells and improve wound healing in mice. Phytomedicine 21, 247-253. doi: 10.1016/j.phymed.2013.09.003

Gangwar, M., Gautam, M. K., Ghildiyal, S., Nath, G., and Goel, R. K. (2015). Mallotus philippinensis Muell. Arg fruit glandular hairs extract promotes wound healing on different wound model in rats. BMC Complement. Altern. Med. 15:123. doi: 10.1186/s12906-015-0647-y

Grof, C. P. L. (2018). Cannabis, from plant to pill. Br. J. Clin. Pharmacol. 84, 2463-2467. doi: 10.1111/bcp.13618

Guo, L. H., Cao, Y., Zhuang, R. T., Han, Y., and Li, J. (2019). Astragaloside IV promotes the proliferation and migration of osteoblast-like cells through the hedgehog signaling pathway. Int. J. Mol. Med. 43, 830-838. doi: 10.3892/ijmm. 2018.4013

Han, X. J., Li, H., Liu, C. B., Luo, Z. R., Wang, Q. L., Mou, F. F., et al. (2019). Guanxin Danshen formulation improved the effect of mesenchymal stem cells transplantation for the treatment of myocardial infarction probably via enhancing the engraftment. Life Sci. 233:116740. doi: 10.1016/j.lfs.2019.116740

Heo, J. S., Lee, S. G., and Kim, H. O. (2017). Distal-less homeobox 5 is a master regulator of the osteogenesis of human mesenchymal stem cells. Int. J. Mol. Med. 40, 1486-1494. doi: 10.3892/ijmm.2017.3142

Hryhorowicz, S., Walczak, M., Zakerska-Banaszak, O., Slomski, R., and Skrzypczak-Zielinska, M. (2018). Pharmacogenetics of cannabinoids. Eur. J. Drug Metab. Pharmacokinet. 43:1. doi: 10.1007/s13318-017-0416-z

Hu, L., Liu, Y., Wang, B., Wu, Z., Chen, Y., Yu, L., et al. (2019). MiR-539-5p negatively regulates migration of rMSCs induced by Bushen Huoxue decoction through targeting Wnt5a. Int. J. Med. Sci. 16, 998-1006. doi: 10.7150/ijms. 33437

Huang, N., Li, Y., Zhou, Y., Zhou, Y., Feng, F., Shi, S., et al. (2019). Neuroprotective effect of tanshinone IIA-incubated mesenchymal stem cells on Aß25-35induced neuroinflammation. Behav. Brain Res. 365, 48-55. doi: 10.1016/j.bbr. 2019.03.001

Idris, A. I., and Ralston, S. H. (2012). Role of cannabinoids in the regulation of bone remodeling. Front. Endocrinol. 3:136. doi: 10.3389/fendo.2012.00136

Iinuma, S., Aikawa, E., Tamai, K., Fujita, R., Kikuchi, Y., Chino, T., et al. (2015). Transplanted bone marrow-derived circulating PDGFR $\alpha+$ cells restore type 
VII collagen in recessive dystrophic epidermolysis bullosa mouse skin graft. J. Immunol. 194, 1996-2003. doi: 10.4049/jimmunol.1400914

Jiao, F., Tang, W., Huang, H., Zhang, Z., Liu, D., Zhang, H., et al. (2018). Icariin promotes the migration of BMSCs in vitro and in vivo via the MAPK signaling pathway. Stem Cells Int. 2018:2562105. doi: 10.1155/2018/2562105

Ju, D. T., Kuo, W. W., Ho, T. J., Paul, C. R., Kuo, C. H., Viswanadha, V. P., et al. (2015). Protocatechuic acid from Alpinia oxyphylla induces Schwann cell migration via ERK1/2, JNK and p38 activation. Am. J. Chin Med. 43, 653-665. doi: $10.1142 / \mathrm{s} 0192415 \times 15500408$

Justus, C. R., Leffler, N., Echevarria, M. R., and Yang, L. V. (2014). In vitro cell migration and invasion assays. J. Vis. Exp. 88:e51046. doi: 10.3791/51046

Kamali, A., Oryan, A., Hosseini, S., Ghanian, M. H., Alizadeh, M., Baghaban Eslaminejad, M., et al. (2019). Cannabidiol-loaded microspheres incorporated into osteoconductive scaffold enhance mesenchymal stem cell recruitment and regeneration of critical-sized bone defects. Mater. Sci. Eng. C. 101, 64-75. doi: 10.1016/j.msec.2019.03.070

Karanjgaokar, C. G., Radhakrishnan, P. V., and Venkataraman, K. (1967). Morelloflavone, a 3-(8-) flavonylflavanone, from the heartwood of Garcinia morella. Tetrahedron Lett. 8, 3195-3198. doi: 10.1016/s0040-4039(01)89897-x

Kaur, R., Ambwani, S. R., and Singh, S. (2016). Endocannabinoid system: a multifacet therapeutic target. Curr. Clin. Pharmacol. 11, 110-117. doi: 10.2174/ 1574884711666160418105339

Khan, A. K., Rashid, R., Fatima, N., Mahmood, S., Mir, S., Khan, S., et al. (2015). Pharmacological activities of protocatechuic acid. Acta Pol. Pharm. 72, 643-650.

Kim, K. H., Blasco-Morente, G., Cuende, N., and Arias-Santiago, S. (2017). Mesenchymal stromal cells: properties and role in management of cutaneous diseases. J. Eur. Acad. Dermatol. Venereol. 31, 414-423. doi: 10.1111/jdv.13934

Kong, D., Liu, Q., Xu, G., Huang, Z., Luo, N., Huang, Y., et al. (2017). Synergistic effect of tanshinone IIA and mesenchymal stem cells on preventing learning and memory deficits via anti-apoptosis, attenuating tau phosphorylation and enhancing the activity of central cholinergic system in vascular dementia. Neurosci. Lett. 637, 175-181. doi: 10.1016/j.neulet.2016.11.024

Kong, X., Zhong, M., Su, X., Qin, Q., Su, H., Wan, H., et al. (2016). Tetramethylpyrazine promotes migration of neural precursor cells via activating the phosphatidylinositol 3-kinase pathway. Mol. Neurobiol. 53, 65266539. doi: 10.1007/s12035-015-9551-1

Krueger, T. E. G., Thorek, D. L. J., Denmeade, S. R., Isaacs, J. T., and Brennen, W. N. (2018). Concise review: mesenchymal stem cell-based drug delivery: the good, the bad, the ugly, and the promise. Stem Cells Transl. Med. 7, 651-663. doi: $10.1002 / \mathrm{sctm} .18-0024$

Lee, H. P., Liu, Y. C., Chen, P. C., Tai, H. C., Li, T. M., and Fong, Y. C. (2017). Tanshinone IIA inhibits angiogenesis in human endothelial progenitor cells in vitro and in vivo. Oncotarget 8, 109217-109227. doi: 10.18632/oncotarget. 22649

Li, C., Li, Q., Mei, Q., and Lu, T. (2015). Pharmacological effects and pharmacokinetic properties of icariin, the major bioactive component in Herba Epimedii. Life Sci. 126, 57-68. doi: 10.1016/j.lff.2015.01.006

Li, K., Song, J., Zhao, Q., Wang, B., Zhang, Y., Wang, X., et al. (2018). Effective component of Salvia miltiorrhiza in promoting cardiomyogenic differentiation of human placenta-derived mesenchymal stem cells. Int. J. Mol. Med. 41, 962-968. doi: 10.3892/ijmm.2017.3293

Li, L., Chu, L., Fang, Y., Yang, Y., Qu, T., Zhang, J., et al. (2017a). Preconditioning of bone marrow-derived mesenchymal stromal cells by tetramethylpyrazine enhances cell migration and improves functional recovery after focal cerebral ischemia in rats. Stem Cell Res. Ther. 8:112. doi: 10.1186/s13287-0170565-7

Li, L., Chu, L., Ren, C., Wang, J., Sun, S., Li, T., et al. (2019). Enhanced migration of bone marrow-derived mesenchymal stem cells with tetramethylpyrazine and its synergistic effect on angiogenesis and neurogenesis after cerebral ischemia in rats. Stem Cells Dev. 228, 871-881. doi: 10.1089/scd.2018. 0254

Li, L., Hou, X., Xu, R., Liu, C., and Tu, M. (2017b). Research review on the pharmacological effects of astragaloside IV. Fundam. Clin. Pharmacol. 31, 17-36. doi: $10.1111 /$ fcp. 12232

Li, Z., Xu, S., and Liu, P. (2018a). Salvia miltiorrhiza Burge (Danshen): a golden herbal medicine in cardiovascular therapeutics. Acta Pharmacol. Sin. 39, 802824. doi: 10.1038 /aps.2017.193
Li, Z., Zhang, S., Cao, L., Li, W., Ye, Y. C., Shi, Z. X., et al. (2018b). Tanshinone IIA and Astragaloside IV promote the angiogenesis of mesenchymal stem cell-derived endothelial cell-like cells via upregulation of Cx37, Cx40 and Cx43. Exp. Ther. Med. 15, 1847-1854. doi: 10.3892/etm.2018. 6428

Liu, C., Qi, X., Alhabeil, J., Lu, H., and Zhou, Z. (2019). Activation of cannabinoid receptors promote periodontal cell adhesion and migration. J. Clin. Periodontol. 46, 1264-1272. doi: $10.1111 /$ jcpe. 13190

Liu, D., Ye, Y., Xu, L., Yuan, W., and Zhang, Q. (2018). Icariin and mesenchymal stem cells synergistically promote angiogenesis and neurogenesis after cerebral ischemia via PI3K and ERK1/2 pathways. Biomed. Pharmacother. 108, 663-669. doi: 10.1016/j.biopha.2018.09.071

Liu, H. J., Liu, X. Y., and Jing, D. B. (2018). Icariin induces the growth, migration and osteoblastic differentiation of human periodontal ligament fibroblasts by inhibiting Toll-like receptor 4 and NF-kB p65 phosphorylation. Mol. Med. Rep. 18, 3325-3331. doi: 10.3892/mmr.2018.9302

Liu, R.-X., Wang, Q., Guo, H. Z., Li, L., Bi, K. S., and Guo, D. A. (2005). Simultaneous determination of 10 major flavonoids in Dalbergia odorifera by high performance liquid chromatography. J. Pharm. Biomed. Anal. 39, 469-476. doi: 10.1016/j.jpba.2005.04.007

Liu, S., Stroncek, D. F., Zhao, Y., Chen, V., Shi, R., Chen, J., et al. (2019). Single cell sequencing reveals gene expression signatures associated with bone marrow stromal cell subpopulations and time in culture. J. Transl. Med. 17:23. doi: 10.1186/s12967-018-1766-2

Liu, X., Niu, Y., Xie, W., Wei, D., and Du, Q. (2019). Tanshinone IIA promotes osteogenic differentiation of human periodontal ligament stem cells via ERK1/2-dependent Runx2 induction. Am. J. Transl. Res. 11, 340-350.

Liu, Y. D., Sun, X., Zhang, Y., Wu, H. J., Wang, H., and Yang, R. (2019). Protocatechuic acid inhibits TGF-ß1-induced proliferation and migration of human airway smooth muscle cells. J. Pharmacol. Sci. 139, 9-14. doi: 10.1016/j. jphs.2018.10.011

Liu, Y. M., Li, W. Y., Xu, L. L., Yu, L. J., Luo, Y. W., Li, X. C., et al. (2019). Catharmus tinctorius volatile oil promote the migration of mesenchymal stem cells via ROCK2/Myosin light chain signaling. Chin. J. Nat. Med. 17, 506-516. doi: 10.1016/s1875-5364(19)30072-x

López, J. J., Jardín, I., Salido, G. M., and Rosado, J. A. (2008). Cinnamtannin B1 as an antioxidant and platelet aggregation inhibitor. Life Sci. 82, 977-982. doi: $10.1016 /$ j.lfs.2008.03.009

Lüder, E., Ramer, R., Peters, K., and Hinz, B. (2017). Decisive role of P42/44 mitogen-activated protein kinase in $\Delta 9$-tetrahydrocannabinol-induced migration of human mesenchymal stem cells. Oncotarget 8, 105984-105994. doi: 10.18632/oncotarget.22517

Marquez-Curtis, L. A., and Janowska-Wieczorek, A. (2013). Enhancing the migration ability of mesenchymal stromal cells by targeting the SDF1/CXCR4 axis. Biomed. Res. Int. 2013:561098. doi: 10.1155/2013/56 1098

Meng, S. S., Xu, X. P., Chang, W., Lu, Z. H., Huang, L. L., Xu, J. Y., et al. (2018). LincRNA-p21 promotes mesenchymal stem cell migration capacity and survival through hypoxic preconditioning. Stem Cell Res. Ther. 9:280. doi: 10.1186/ s13287-018-1031-x

Mi, B., Liu, J., Liu, G., Zhou, W., Liu, Y., Hu, L., et al. (2018). Icariin promotes wound healing by enhancing the migration and proliferation of keratinocytes via the AKT and ERK signaling pathway. Int. J. Mol. Med. 42, 831-838. doi: $10.3892 /$ ijmm.2018.3676

Mohr, A., and Zwacka, R. (2018). The future of mesenchymal stem cell-based therapeutic approaches for cancer - from cells to ghosts. Cancer Lett. 414, 239-249. doi: 10.1016/j.canlet.2017.11.025

Nitzsche, F., Müller, C., Lukomska, B., Jolkkonen, J., Deten, A., and Boltze, J. (2017). Concise review: MSC adhesion cascade-insights into homing and transendothelial migration. Stem Cells 35, 1446-1460. doi: 10.1002/stem. 2614

Park, J. S., Suryaprakash, S., Lao, Y. H., and Leong, K. W. (2015). Engineering mesenchymal stem cells for regenerative medicine and drug delivery. Methods 84, 3-16. doi: 10.1016/j.ymeth.2015.03.002

Pertwee, R. G. (2008). The diverse CB1 and CB2 receptor pharmacology of three plant cannabinoids: delta9-tetrahydrocannabinol, cannabidiol and delta9tetrahydrocannabivarin. Br. J. Pharmacol. 153, 199-215. doi: 10.1038/sj.bjp. 0707442 
Pittenger, M. F., Discher, D. E., Péault, B. M., Phinney, D. G., Hare, J. M., and Caplan, A. I. (2019). Mesenchymal stem cell perspective: cell biology to clinical progress. NPJ Regen. Med. 4:22. doi: 10.1038/s41536-0190083-6

Presen, D. M., Traweger, A., Gimona, M., and Redl, H. (2019). Mesenchymal stromal cell-based bone regeneration therapies: from cell transplantation and tissue engineering to therapeutic secretomes and extracellular vesicles. Front. Bioeng. Biotechnol. 7:352. doi: 10.3389/fbioe.2019. 00352

Qian, K., Xu, H., Dai, T., and Shi, K. (2015). Effects of Tanshinone IIA on osteogenic differentiation of mouse bone marrow mesenchymal stem cells. Naunyn Schmiedebergs Arch. Pharmacol. 388, 1201-1209. doi: 10.1007/s00210015-1154-x

Qin, S., Zhou, W., Liu, S., Chen, P., and Wu, H. (2015). Icariin stimulates the proliferation of rat bone mesenchymal stem cells via ERK and p38 MAPK signaling. Int. J. Clin. Exp. Med. 8, 7125-7133.

Ren, J., Fu, L., Nile, S. H., Zhang, J., and Kai, G. (2019). Salvia miltiorrhiza in treating cardiovascular diseases: a review on its pharmacological and clinical applications. Front. Pharmacol. 10:753. doi: 10.3389/fphar.2019.00753

Rivera-Barreno, R., del Castillo-Vaquero, A., Salido, G. M., and Gonzalez, A. (2010). Effect of cinnamtannin B-1 on cholecystokinin-8-evoked responses in mouse pancreatic acinar cells. Clin. Exp. Pharmacol. Physiol. 37, 980-988. doi: 10.1111/j.1440-1681.2010.05424.x

Rivera-Piza, A., An, Y. J., Kim, D. K., Lee, S. H., Kim, J. B., Choi, J. S., et al. (2017). Protocatechuic acid enhances osteogenesis, but inhibits adipogenesis in C3H10T1/2 and 3T3-L1 cells. J. Med. Food. 20, 309-319. doi: 10.1089/jmf.2016. 3833

Rochefort, G. Y., Delorme, B., Lopez, A., Herault, O., Bonnet, P., Charbord, P., et al. (2006). Multipotential mesenchymal stem cells are mobilized into peripheral blood by hypoxia. Stem Cells 24, 2202-2208. doi: 10.1634/stemcells.2006-0164

Ruan, X. F., Ju, C. W., Shen, Y., Liu, Y. T., Kim, I. M., Yu, H., et al. (2018). Suxiao Jiuxin pill promotes exosome secretion from mouse cardiac mesenchymal stem cells in vitro. Acta Pharmacol. Sin. 39, 569-578. doi: 10.1038/aps.2018.19

Sánchez-Rubio, F., Fernández-Santos, M. R., Castro-Vázquez, L., García-Álvarez, O., Maroto-Morales, A., Soler, A. J., et al. (2018). Cinnamtannin B-1, a novel antioxidant for sperm in red deer. Anim. Reprod. Sci. 195, 44-52. doi: 10.1016/ j.anireprosci.2018.05.004

Schicho, R., Bashashati, M., Bawa, M., McHugh, D., Saur, D., Hu, H. M., et al. (2011). The atypical cannabinoid O-1602 protects against experimental colitis and inhibits neutrophil recruitment. Inflamm. Bowel Dis. 17, 1651-1664. doi: 10.1002/ibd.21538

Schmuhl, E., Ramer, R., Salamon, A., Peters, K., and Hinz, B. (2014). Increase of mesenchymal stem cell migration by cannabidiol via activation of p42/44 MAPK. Biochem. Pharmacol. 87, 489-501. doi: 10.1016/j.bcp.2013. 11.016

Shedoeva, A., Leavesley, D., Upton, Z., and Fan, C. (2019). Wound healing and the use of medicinal plants. Evid. Based Complement Alternat. Med. 2019, 2684108. doi: 10.1155/2019/2684108

Shen, W., Luo, H., Xu, L., Wu, Z., Chen, H., Liu, Y., et al. (2018). Wnt5a mediates the effects of Bushen Huoxue decoction on the migration of bone marrow mesenchymal stem cells in vitro. Chin. Med. 13:45. doi: 10.1186/s13020-0180200-2

Song, H., and Ren, J. (2019). Protocatechuic acid attenuates angiotensin II-induced cardiac fibrosis in cardiac fibroblasts through inhibiting the NOX4/ROS/p38 signaling pathway. Phytother. Res. 33, 2440-2447. doi: 10.1002/ptr.6435

Song, X., Dai, J., Li, H., Li, Y., Hao, W., Zhang, Y., et al. (2019). Anti-aging effects exerted by tetramethylpyrazine enhances self-renewal and neuronal differentiation of rat bMSCs by suppressing NF-kB signaling. Biosci. Rep. 39:BSR20190761. doi: 10.1042/bsr20190761

Tong, Y., Xu, W., Han, H., Chen, Y., Yang, J., Qiao, H., et al. (2011). Tanshinone IIA increases recruitment of bone marrow mesenchymal stem cells to infarct region via up-regulating stromal cell-derived factor-1/CXC chemokine receptor 4 axis in a myocardial ischemia model. Phytomedicine 18, 443-450. doi: 10.1016/j. phymed.2010.10.009

Uccelli, A., Moretta, L., and Pistoia, V. (2008). Mesenchymal stem cells in health and disease. Nat. Rev. Immunol. 8, 726-736. doi: 10.1038/nri2395

Vaccani, A., Massi, P., Colombo, A., Rubino, T., and Parolaro, D. (2005). Cannabidiol inhibits human glioma cell migration through a cannabinoid receptor-independent mechanism. Br. J. Pharmacol. 144, 1032-1036. doi: 10 1038/sj.bjp.0706134

Wan, J. B., Li, S. P., Chen, J. M., and Wang, Y. T. (2007). Chemical characteristics of three medicinal plants of the Panax genus determined by HPLC-ELSD. J. Sep. Sci. 30, 825-832. doi: 10.1002/jssc.2006 00359

Wang, D., Liu, Y., Zhong, G., Wang, Y., Zhang, T., Zhao, Z., et al. (2017). Compatibility of Tanshinone IIA and Astragaloside IV in attenuating hypoxiainduced cardiomyocytes injury. J. Ethnopharmacol. 204, 67-76. doi: 10.1016/j. jep.2017.03.053

Wang, F., Tang, H., Zhu, J., and Zhang, J. H. (2018). Transplanting mesenchymal stem cells for treatment of ischemic stroke. Cell Transplant. 27, 1825-1834. doi: 10.1177/0963689718795424

Wang, H., Liu, T. Q., Zhu, Y. X., Guan, S., Ma, X. H., and Cui, Z. F. (2009). Effect of protocatechuic acid from Alpinia oxyphylla on proliferation of human adipose tissue-derived stromal cells in vitro. Mol. Cell Biochem. 330, 47-53. doi: 10.1007/s11010-009-0099-0

Wang, H., Liu, T.-Q., Guan, S., Zhu, Y.-X., and Cui, Z.-X. (2008). Protocatechuic acid from Alpinia oxyphylla promotes migration of human adipose tissuederived stromal cells in vitro. Eur. J. Pharmacol. 599, 24-31. doi: 10.1016/j. ejphar.2008.09.030

Wang, L. L., Zhao, R., Li, J. Y., Li, S. S., Liu, M., Wang, M., et al. (2016). Pharmacological activation of cannabinoid 2 receptor attenuates inflammation, fibrogenesis, and promotes re-epithelialization during skin wound healing. Eur. J. Pharmacol. 786, 128-136. doi: 10.1016/j.ejphar.2016.06.006

Wang, X., Liu, C., Xu, Y., Chen, P., Shen, Y., Xu, Y., et al. (2017). Combination of mesenchymal stem cell injection with icariin for the treatment of diabetesassociated erectile dysfunction. PloS One 12:e0174145. doi: 10.1371/journal. pone. 0174145

Wang, Y., Peng, H., Shen, Y., Zhao, R., and Huang, L. (2013). The profiling of bioactive ingredients of differently aged Salvia miltiorrhiza roots. Microsc. Res. Tech. 76, 947-954. doi: 10.1002/jemt.22253

Wang, Z. C., Sun, H. J., Li, K. H., Fu, C., and Liu, M. Z. (2014). Icariin promotes directed chondrogenic differentiation of bone marrow mesenchymal stem cells but not hypertrophy in vitro. Exp. Ther. Med. adeh, A., and Connelly, K. A. (2018). Concise review: rational use of mesenchymal stem cells in the treatment of ischemic heart disease. Stem Cells Transl. Med. 7, 543-550. doi: 10.1002/sctm. 17-0210

Ward, M. R., Abadeh, A., and Connelly, K. A. (2018). Concise review: rational use of mesenchymal stem cells in the treatment of ischemic heart disease. Stem Cells Transl. Med. 7, 543-550. doi: 10.1002/sctm.17-0210

Wu, Y., Zhao, R. C., and Tredget, E. E. (2010). Concise review: bone marrowderived stem/progenitor cells in cutaneous repair and regeneration. Stem Cells 28, 905-915. doi: 10.1002/stem.420

Xie, J., Wang, H., Song, T., Wang, Z., Li, F., Ma, J., et al. (2013). Tanshinone IIA and astragaloside IV promote the migration of mesenchymal stem cells by up-regulation of CXCR4. Protoplasma 250, 521-530. doi: 10.1007/s00709-0120435-1

Xing, Y., Tu, J., Zheng, L., Guo, L., and Xi, T. (2015). Anti-angiogenic effect of tanshinone IIA involves inhibition of the VEGF/VEGFR2 pathway in vascular endothelial cells. Oncol. Rep. 33, 163-170. doi: 10.3892/or.2014. 3592

Xu, X. L., Ji, H., Gu, S. Y., Shao, Q., Huang, Q. J., and Cheng, Y. P. (2007). Modification of alterations in cardiac function and sarcoplasmic reticulum by astragaloside IV in myocardial injury in vivo. Eur. J. Pharmacol. 568, 203-212. doi: 10.1016/j.ejphar.2007.04.007

Yang, L., Wang, Y., Wang, X., and Liu, Y. (2015). Effect of allogeneic umbilical cord mesenchymal stem cell transplantation in a rat model of hepatic cirrhosis. J. Tradit. Chin. Med. 35, 63-68. doi: 10.1016/s0254-6272(15) 30010-8

Yin, K., Wang, S., and Zhao, R. C. (2019). Exosomes from mesenchymal stem/stromal cells: a new therapeutic paradigm. Biomark. Res. 7, 8. doi: 10.1186/ s40364-019-0159-x

Zhang, M., Gao, F., Teng, F., and Zhang, C. (2014). Tetramethylpyrazine promotes the proliferation and migration of brain endothelial cells. Mol. Med. Rep. 10, 29-32. doi: 10.3892/mmr.2014.2169

Zhang, X. M., Ma, J., Sun, Y., Yu, B. Q., Jiao, Z. M., Wang, D., et al. (2018). Tanshinone IIA promotes the differentiation of bone marrow mesenchymal 
stem cells into neuronal-like cells in a spinal cord injury model. J. Transl. Med. 16, 193. doi: 10.1186/s12967-018-1571-y

Zhao, Y., Liu, Y., and Chen, K. (2016). Mechanisms and clinical application of tetramethylpyrazine (an interesting natural compound isolated from Ligusticum Wallichii): Current status and perspective. Oxid. Med. Cell. Longev. 2016, 2124638. doi: 10.1155/2016/2124638

Zhu, H., Wang, X., Han, Y., Zhang, W., Xin, W., Zheng, X., et al. (2018). Icariin promotes the migration of bone marrow stromal cells via the SDF-1 $\alpha / \mathrm{HIF}-$ 1 $\alpha /$ CXCR4 pathway. Drug Des. Devel. Ther. 12, 4023-4031. doi: 10.2147/dddt. s179989
Conflict of Interest: The author declares that the research was conducted in the absence of any commercial or financial relationships that could be construed as a potential conflict of interest.

Copyright $\odot 2020$ Maeda. This is an open-access article distributed under the terms of the Creative Commons Attribution License (CC BY). The use, distribution or reproduction in other forums is permitted, provided the original author(s) and the copyright owner(s) are credited and that the original publication in this journal is cited, in accordance with accepted academic practice. No use, distribution or reproduction is permitted which does not comply with these terms. 